\title{
Universiteit
}

Leiden

The Netherlands

\section{Physically active lessons in schools and their impact on physical activity, educational, health and cognition outcomes: a systematic review and meta-analysis}

Norris, E.; Steen, T. van; Direito, A.; Stamatakis, E.

\section{Citation}

Norris, E., Steen, T. van, Direito, A., \& Stamatakis, E. (2019). Physically active lessons in schools and their impact on physical activity, educational, health and cognition outcomes: a systematic review and meta-analysis. British Journal Of Sports Medicine, 54(14), 826-838. doi:10.1136/bjsports-2018-100502

Version: Publisher's Version

License: $\quad$ Licensed under Article 25fa Copyright Act/Law (Amendment Taverne)

Downloaded from: https://hdl.handle.net/1887/85663

Note: To cite this publication please use the final published version (if applicable). 


\title{
Physically active lessons in schools and their impact on physical activity, educational, health and cognition outcomes: a systematic review and meta-analysis
}

\author{
Emma Norris (1) , ${ }^{1}$ Tommy van Steen 다, ${ }^{2}$ Artur Direito (다, \\ Emmanuel Stamatakis (1) ${ }^{4}$
}

- Additional material is published online only. To view please visit the journal online (http://dx.doi.org/10.1136/ bjsports-2018-100502).

${ }^{1}$ Centre for Behaviour Change, University College London, London, UK

${ }^{2}$ Institute of Security and Global Affairs, Leiden University, Leiden, The Netherlands

${ }^{3}$ Yong Loo Lin School of

Medicine, National University of Singapore, Singapore, Singapore ${ }^{4}$ School of Public Health, University of Sydney, Sydney, New South Wales, Australia

\section{Correspondence to}

Dr Emma Norris, Centre for Behaviour Change, University College London, London WC1E 7HB, UK;

emma.norris@ucl.ac.uk

Accepted 10 September 2019

Check for updates

(c) Author(s) (or their employer(s)) 2019. No commercial re-use. See rights and permissions. Published by BMJ.

To cite: Norris $\mathrm{E}$, van Steen T, Direito A, et al. Br I Sports Med Epub ahead of print: [please include Day Month Year]. doi:10.1136/ bjsports-2018-100502

\section{ABSTRACT}

Objective This review provides the first meta-analysis of the impact of physically active lessons on lesson-time and overall physical activity (PA), as well as health, cognition and educational outcomes.

Design Systematic review and meta-analysis of controlled studies. Six meta-analyses pooled effects on lesson-time PA, overall PA, in-class educational and overall educational outcomes, cognition and health outcomes. Meta-analyses were conducted using the metafor package in R. Risk of bias was assessed using the Cochrane tool for risk of bias.

Data sources PubMed, Embase, PsycINFO, ERIC and Web of Science, grey literature and reference lists were searched in December 2017 and April 2019.

Studies eligibility criteria Physically active lessons compared with a control group in a randomised or non-randomised design, within single component interventions in general school populations.

Results 42 studies (39 in preschool or elementary school settings, 27 randomised controlled trials) were eligible to be included in the systematic review and 37 of them were included across the six meta-analyses $(n=12663)$. Physically active lessons were found to produce large, significant increases in lesson-time PA ( $d=2.33 ; 95 \% \mathrm{Cl} 1.42$ to $3.25: k=16)$ and small, increases on overall PA $(d=0.32 ; 95 \% \mathrm{Cl} 0.18$ to 0.46 : $k=8)$, large, improvement in lesson-time educational outcomes ( $d=0.81 ; 95 \% \mathrm{Cl} 0.47$ to $1.14: k=7)$ and a small improvement in overall educational outcomes $(d=0.36 ; 95 \% \mathrm{Cl} 0.09$ to $0.63: k=25)$. No effects were seen on cognitive $(k=3)$ or health outcomes $(k=3)$. 25/42 studies had high risk of bias in at least two domains.

Conclusion In elementary and preschool settings, when physically active lessons were added into the curriculum they had positive impact on both physical activity and educational outcomes. These findings support policy initiatives encouraging the incorporation of physically active lessons into teaching in elementary and preschool setting.

Trial registration number CRD42017076933.

\section{INTRODUCTION}

Globally around $50 \%$ of children ${ }^{1}$ and $80 \%$ of adolescents $^{2}$ do not obtain the $60 \mathrm{~min}$ of moderate-to-vigorous physical activity (MVPA) per day recommended by the WHO. ${ }^{3}$ Classroom time is consistently shown to be the greatest contributor of sedentary time in children, ${ }^{4}$ with obligatory teacher-led lessons contributing around 7 to 8 hours of sedentary time per day. ${ }^{5}$ Increasing awareness of the health, ${ }^{6}$ cognitive $^{7}$ and mental health benefits ${ }^{89}$ of physical activity has led governments to recommend at least 30 min of MVPA per school day. ${ }^{3} 10$ Schools provide an ideal environment to increase physical activity, as they allow prolonged access to the majority of children. ${ }^{11} 12$ However, time constraints and education priorities make it difficult for teachers and schools to integrate activity opportunities into the school routine. ${ }^{13} 14$

Physically active lessons (also known as physically active learning ${ }^{15}$ ) combine physical activity with academic content and have been explored as a potential method of increasing activity in schools without detriment to educational time. ${ }^{16}$ Examples of physically active lessons include doing star jumps while reciting times tables ${ }^{17}$ or using movements to show whether an answer is true or false. ${ }^{18}$ Embedded physical activity can be specifically relevant to the learning task at-hand, or task non-relevant but still occurring simultaneously in the taught session. ${ }^{19}$ Such activities also can take place inside or outdoors. Physically active lessons are distinct from 'brain' or 'active breaks' which allow bouts of in-class activity without educational content. ${ }^{20}$

Previous systematic reviews have collated research evidence for physically active lessons through qualitative syntheses. ${ }^{152021}$ These have identified mostly positive results on physical activity, health and educational outcomes across a wide range of study designs. However, it was not possible to synthesise findings identified in previous reviews due to the relative small number of studies. ${ }^{20} \mathrm{~A}$ recent review assessed classroom-based general physical activity interventions including active breaks and other approaches, with 13/39 studies comprising of physically active lesson interventions. ${ }^{22}$ This found classroom-based interventions to have a significant, positive effect on improving time-ontask and academic achievement, but no effects on cognitive functions or physical activity. ${ }^{22}$ However, that review did not include a meta-analysis of the effects of physically active lessons specifically. Other reviews have meta-analysed physically active lessons among other school-based interventions, such as to explore effects on student engagement ${ }^{23}$ and academic performance. ${ }^{24}$

This review extends previous attempts to synthesise research by meta-analysing the effects of physically active lessons compared with typical teaching. This review aimed to assess the impact and moderators of physically active lessons on physical activity, educational, health and cognition outcomes. 
1. physical activity or exercis* or movement* (title and abstract)

2. class* or lesson* or learn* (title and abstract)

\section{3. child* or young* or pupil* (title and abstract)}

\section{1 and 2 and 3}

Figure 1 Search strategy used in PubMed.

\section{METHODS}

The review protocol was registered with PROSPERO $^{25}$ and Preferred Reporting Items for Systematic Reviews and Meta-Analyses guidelines for systematic review reporting ${ }^{26}$ were followed.

\section{Search strategy and information sources}

In December 2017, a systematic search was conducted using PubMed, Embase, PsycINFO, ERIC and Web of Science electronic databases. Searches were re-run in April 2019. Search terms included: (1) physical activity, exercise or movement, (2) class, lesson or learning and (3) children, young or pupil, all combined with 'AND' (figure 1). Grey literature from related organisations was also searched, such as the Education Endowment Foundation (UK), Play England (UK), Active Living Research (USA) \& Active Academics (USA). We also manually searched the reference lists of review studies.

\section{Inclusion and exclusion criteria}

Physically active lessons were required to be carried out in schools, with studies requiring a control group (eg, randomised or non-randomised controlled trials) to evaluate the effects of physically active lessons. Authors of related conference proceeding titles or abstracts were contacted for full text reports. Searches were restricted to English language studies published from January 1997.

Physically active lessons as part of multicomponent interventions were excluded as it would have been nearly impossible to isolate their independent effects. Studies conducted in labs, testing physical education, physical activity breaks without educational content, after-school or recess interventions were excluded. Studies with exclusively special populations (such as children with Special Educational Needs or obesity) were excluded. Studies exclusively reporting protocol, qualitative or process evaluation findings were excluded. Reviews were also excluded although reference lists were searched. Studies meeting all criteria were included regardless of sample size, to reflect the variation of study sizes conducted to date.

\section{Study selection and data extraction}

Search results were imported into Covidence ${ }^{27}$ and duplicates removed. Titles, abstracts and full texts were screened by EN, $\mathrm{AD}$ and TvS, with disagreements discussed between these two authors. All data from included studies were extracted onto a standardised, pre-piloted Excel form between February 2018 and April 2018 and after searches were re-run in April 2019. Data extraction was informed by the Template for Intervention Description and Replication (TIDieR) ${ }^{28}$ checklist. Behaviour Change Techniques (BCTs) or the 'active ingredients' intended to elicit change in teachers and pupils were coded in identified studies by two independent coders (EN and AD) using the BCT Taxonomy $\mathrm{v} 1^{29}$ addressing the 'What' component of TIDieR. Data were extracted from study protocols where available.
Outcome measurement methods and instruments were extracted related to physical activity (eg, questionnaires, observations, accelerometry), education (eg, time-on-task (often also referred to as on-task behaviour), academic achievement), health (eg, body mass index (BMI)) and cognition (eg, fluid intelligence and executive function, not time-on-task) with results extracted across all reported time-points. Data was only extracted where reported for both active lesson and control groups for example, not extracted where activity assessed during active lessons only. Data was independently extracted by two reviewers (split between $\mathrm{EN}, \mathrm{AD}$ and $\mathrm{TvS}$ ) and discrepancies resolved through discussion.

\section{Risk of bias assessment}

Two reviewers (split between EN, AD and TvS) independently assessed risk of bias using the Cochrane collaboration tool for assessing risk of bias. ${ }^{30}$ Assessment was performed for random sequence generation, allocation concealment, blinding of participants and personnel, blinding of outcome assessment, incomplete outcome data and selective reporting. We assessed risk of bias for each criterion as low, unclear or high risk.

\section{Meta-analysis}

Meta-analyses were conducted where there were at least three studies reporting statistics of interest for the same outcome (ie, group Means, SD and N) after contacting authors, for example, cognitive testing, health outcomes, time-on-task. ${ }^{22}$ We contacted authors for any missing required data. A decision strategy was set to prevent the inclusion of multiple outcomes from a single study in any one meta-analysis (eg, two lesson-time physical activity measures such as observed and accelerometer-assessed activity from the same study. ${ }^{22}$ ) For physical activity outcomes, MVPA was prioritised over steps, light activity and sedentary behaviour due to its focus in global physical activity guidelines. ${ }^{3}$ For education outcomes, standardised testing (such as national standardised tests or progress monitoring tools) was prioritised over unstandardised researcher-developed testing. ${ }^{22}$ Mathematical outcomes were prioritised where studies reported multiple subject assessments, as math was the most commonly reported outcome. $^{22}$ Higher scores typically indicated better educational outcomes, so scores were reversed where lower scores reflected better academic-related outcomes. For health outcomes, BMI was prioritised as it was the most commonly reported health outcome in included studies, making it more viable to pool than more heterogeneous health outcomes. Additionally, BMI was prioritised as children's overweight and obesity has greater focus in international child health profiles than other important outcomes, such as children's physical fitness. ${ }^{3} 31$

\section{Analysis strategy}

We used the metafor package for $\mathrm{R}^{32}$ to conduct the meta-analyses with the standardised mean difference Cohen's $d$ with Hedge's $g$ correction as the effect size measure. For the weighting of studies, the inverse variance was computed. We calculated effect sizes and study weights using post-intervention scores of control and intervention groups and where outcomes were measured at multiple time points, we chose the first time point after the intervention had ended as effect size input. In cases where there was no follow-up assessment after the intervention, the final time point was used to calculate the effect size and inverse variance. For studies where only change scores were available, we directly requested the post-test scores from authors via email. 


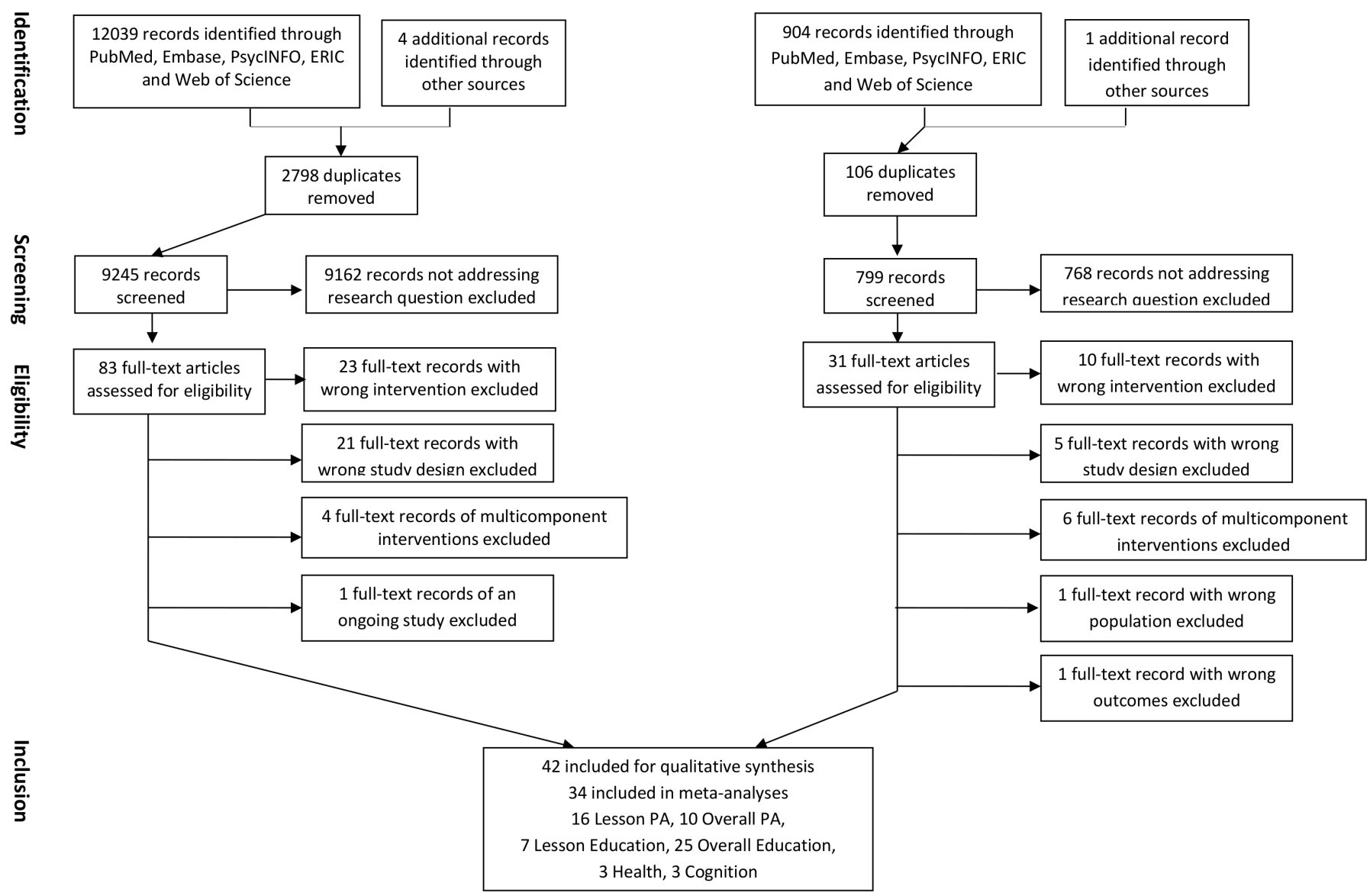

Figure 2 Flow chart for identification of physically active lessons. PA physical activity.

Six random-effects models were fitted to the data, as there was an expectation of heterogeneity between studies due to differences in study design, length and outcome measures. Where applicable, Q-tests were conducted to test the assumption of heterogeneity that underlies the choice for random-effects models. Overall effects were calculated based on Cohen's suggestion of small/medium/large effect size estimates of 0.3 , 0.5 and 0.8 , respectively, ${ }^{33}$ with additional sensitivity analysis performed using the leave-one-out method. We used the trimand-fill method ${ }^{34}$ to investigate possible publication bias in the included comparisons.

\section{Moderators}

Moderator analyses assessed the robustness of the overall effect sizes. Seven dichotomous moderators were coded for: (1) risk of bias (high vs low - studies with at least one domain assessed as 'high risk of bias' were considered to have high risk of bias; excluding the blinding domain due to all studies assessed at high risk), (2) randomised controlled trial design (RCT vs not), (3) intervention length ( $>8$ weeks vs $<8$ weeks - the median intervention length), (4) number of intervention sessions (oneoff physically active lessons vs more than one), (5) school type (preschool vs elementary school or higher), (6) source of intervention delivery (existing classroom teachers vs recruited personnel including teachers or research staff) and (7) subjective vs objective (self-report vs objectively measured physical activity via pedometer or accelerometer). All six meta-analyses tested the first six moderators, whilst only the overall physical activity and lesson-time physical activity meta-analyses tested the physical activity measurement moderator. Differences in outcome variables by gender were not included as a moderator, as gender-stratified outcome data was only reported in 5 out of 42 studies. $^{35-39}$

\section{RESULTS}

\section{Study selection}

The final review included 42 studies (figure 2), reporting the results of 38 trials, where four studies reported findings from the 'Fit en Vaardig op school' trial ${ }^{40-43}$ and two studies reported findings from the 'A+PAAC' trial. ${ }^{3944}$ online supplementary file 1 provides an overview of each study.

\section{Study and participant characteristics}

Eighteen out of 42 studies delivered physically active lessons in the USA, seven in Australia, five in the UK, four in the Netherlands (all the same trial), two in Denmark and one in China, Croatia, Ireland, Israel, Portugal and Sweden respectively (online supplementary file 1). Twenty-seven out of 42 studies were randomised controlled trials, 4 were non-randomised and 11 were quasi-experimental studies. Twenty-nine out of 42 studies delivered interventions in an elementary school setting, nine in preschools, one in preschool into elementary, ${ }^{45}$ one in elementary and middle schools ${ }^{46}$ and two in high school ${ }^{35} 47$ (online supplementary file 1). Intervention length ranged from one-off sessions $^{48-52}$ to 3 years. ${ }^{39445354}$ Of studies providing 
Table 1 Overall effects and subgroup effects of all meta-analyses

\begin{tabular}{|c|c|c|c|c|c|c|c|c|c|}
\hline Meta-analysis & Moderator & Level & $k$ & SMD & $-95 \% \mathrm{Cl}$ & $+95 \% \mathrm{Cl}$ & SE & Z-score & $P$ value \\
\hline \multirow[t]{15}{*}{ Lesson-time physical activity } & Overall effect & - & 16 & 2.33 & 1.42 & 3.25 & 0.47 & 5.00 & $<0.0001$ \\
\hline & \multirow[t]{2}{*}{ Risk of bias } & High risk of bias & 7 & 1.66 & 0.32 & 3.00 & 0.68 & 2.43 & 0.015 \\
\hline & & Low risk of bias & 9 & 2.87 & 1.67 & 4.08 & 0.62 & 4.66 & $<0.0001$ \\
\hline & \multirow[t]{2}{*}{ Study design } & RCT & 14 & 2.46 & 1.46 & 3.46 & 0.51 & 4.84 & $<0.0001$ \\
\hline & & Non-RCT & 2 & 1.45 & -1.19 & 4.08 & 1.34 & 1.08 & 0.28 \\
\hline & \multirow[t]{2}{*}{ Intervention length } & Up to 8 weeks & 12 & 2.30 & 1.21 & 3.40 & 0.56 & 4.13 & $<0.0001$ \\
\hline & & More than 8 weeks & 4 & 2.43 & 0.54 & 4.33 & 0.97 & 2.51 & 0.012 \\
\hline & \multirow[t]{2}{*}{ Number of sessions } & One-off session & 3 & 2.51 & 0.33 & 4.69 & 1.11 & 2.26 & 0.024 \\
\hline & & More than one session & 13 & 2.29 & 1.24 & 3.35 & 0.54 & 4.27 & $<0.0001$ \\
\hline & \multirow[t]{2}{*}{ School type } & Preschool & 5 & 2.67 & 0.96 & 4.37 & 0.87 & 3.07 & 0.002 \\
\hline & & Elementary and over & 11 & 2.19 & 1.06 & 3.32 & 0.58 & 3.79 & 0.0002 \\
\hline & \multirow[t]{2}{*}{ Physical activity measurement } & Objective measurement & 14 & 2.46 & 1.46 & 3.46 & 0.51 & 4.84 & $<0.0001$ \\
\hline & & Subjective measurement & 2 & 1.45 & -1.19 & 4.08 & 1.34 & 1.08 & 0.28 \\
\hline & \multirow[t]{2}{*}{ Intervention delivery } & Existing classroom teacher & 11 & 1.82 & 0.79 & 2.85 & 0.53 & 3.45 & 0.0006 \\
\hline & & Recruited personnel & 5 & 3.46 & 1.91 & 5.02 & 0.79 & 4.38 & $<0.0001$ \\
\hline \multirow[t]{15}{*}{ Overall physical activity } & Overall effect & - & 8 & 0.32 & 0.18 & 0.46 & 0.07 & 4.56 & $<0.0001$ \\
\hline & \multirow[t]{2}{*}{ Risk of bias } & High risk of bias & 6 & 0.28 & 0.12 & 0.44 & 0.08 & 3.44 & 0.0006 \\
\hline & & Low risk of bias & 2 & 0.46 & 0.16 & 0.77 & 0.16 & 2.97 & 0.003 \\
\hline & \multirow[t]{2}{*}{ Study design } & RCT & 8 & 0.32 & 0.18 & 0.46 & 0.07 & 4.56 & $<0.0001$ \\
\hline & & Non-RCT & 0 & - & - & - & - & - & - \\
\hline & \multirow[t]{2}{*}{ Intervention length } & Up to 8 weeks & 7 & 0.30 & 0.15 & 0.44 & 0.08 & 3.89 & 0.0001 \\
\hline & & More than 8 weeks & 1 & 0.51 & 0.07 & 0.95 & 0.22 & 2.29 & 0.0218 \\
\hline & \multirow[t]{2}{*}{ Number of sessions } & One-off session & 1 & 0.03 & -0.49 & 0.55 & 0.27 & 0.11 & 0.9093 \\
\hline & & More than one session & 7 & 0.34 & 0.20 & 0.48 & 0.07 & 4.79 & $<0.0001$ \\
\hline & \multirow[t]{2}{*}{ School type } & Preschool & 0 & - & - & - & - & - & - \\
\hline & & Elementary and over & 8 & 0.32 & 0.18 & 0.46 & 0.07 & 4.56 & $<0.0001$ \\
\hline & \multirow[t]{2}{*}{ Physical activity measurement } & Objective measurement & 8 & 0.32 & 0.18 & 0.46 & 0.07 & 4.56 & $<0.0001$ \\
\hline & & Subjective measurement & 0 & - & - & - & - & - & - \\
\hline & \multirow[t]{2}{*}{ Intervention delivery } & Existing classroom teacher & 7 & 0.32 & 0.17 & 0.48 & 0.08 & 4.05 & $<0.0001$ \\
\hline & & Recruited personnel & 1 & 0.25 & -0.17 & 0.67 & 0.21 & 1.18 & 0.2378 \\
\hline Lesson-time educational & Overall effect & - & 7 & 0.81 & 0.47 & 1.14 & 0.17 & 4.74 & $<0.0001$ \\
\hline outcomes & Risk of bias & High risk of bias & 6 & 0.74 & 0.37 & 1.10 & 0.18 & 3.99 & $<0.0001$ \\
\hline & & Low risk of bias & 1 & 1.21 & 0.34 & 2.08 & 0.44 & 2.72 & 0.0065 \\
\hline & Study design & RCT & 6 & 0.78 & 0.39 & 1.17 & 0.20 & 3.92 & $<0.0001$ \\
\hline & & Non-RCT & 1 & 0.93 & 0.01 & 1.85 & 0.47 & 1.98 & 0.0474 \\
\hline & Intervention length & Up to 8 weeks & 6 & 0.95 & 0.68 & 1.22 & 0.14 & 6.89 & $<0.0001$ \\
\hline & & More than 8 weeks & 1 & 0.20 & -0.35 & 0.75 & 0.28 & 0.73 & 0.4661 \\
\hline & Number of sessions & One-off session & 2 & 1.07 & 0.46 & 1.67 & 0.31 & 3.45 & 0.0006 \\
\hline & & More than one session & 5 & 0.69 & 0.29 & 1.09 & 0.20 & 3.41 & 0.0007 \\
\hline & School type & Preschool & 0 & - & - & - & - & - & - \\
\hline & & Elementary and over & 7 & 0.81 & 0.47 & 1.14 & 0.17 & 4.74 & $<0.0001$ \\
\hline & Intervention delivery & Existing classroom teacher & 6 & 0.74 & 0.37 & 1.10 & 0.18 & 3.99 & $<0.0001$ \\
\hline & & Recruited personnel & 1 & 1.21 & 0.34 & 2.08 & 0.44 & 2.72 & 0.0065 \\
\hline Overall educational & Overall effect & - & 25 & 0.36 & 0.09 & 0.63 & 0.14 & 2.58 & 0.0098 \\
\hline outcomes & Risk of bias & High risk of bias & 15 & 0.34 & -0.03 & 0.70 & 0.19 & 1.80 & 0.0725 \\
\hline & & Low risk of bias & 10 & 0.40 & -0.04 & 0.85 & 0.23 & 1.78 & 0.0755 \\
\hline & Study design & RCT & 12 & 0.40 & 0.00 & 0.80 & 0.20 & 1.97 & 0.0492 \\
\hline & & Non-RCT & 13 & 0.33 & -0.07 & 0.72 & 0.20 & 1.60 & 0.11 \\
\hline & Intervention length & Up to 8 weeks & 14 & 0.46 & 0.09 & 0.82 & 0.19 & 2.44 & 0.0146 \\
\hline & & More than 8 weeks & 11 & 0.24 & -0.16 & 0.64 & 0.20 & 1.18 & 0.24 \\
\hline & Number of sessions & One-off session & 3 & 0.36 & -0.48 & 1.21 & 0.43 & 0.84 & 0.40 \\
\hline & & More than one session & 22 & 0.36 & 0.06 & 0.66 & 0.15 & 2.37 & 0.0179 \\
\hline & School type & Preschool & 7 & 0.70 & 0.22 & 1.18 & 0.24 & 2.85 & 0.0044 \\
\hline & & Elementary and over & 18 & 0.22 & -0.08 & 0.51 & 0.15 & 1.44 & 0.15 \\
\hline & Intervention delivery & Existing classroom teacher & 19 & 0.24 & -0.06 & 0.53 & 0.15 & 1.58 & 0.11 \\
\hline & & Recruited personnel & 6 & 0.73 & 0.20 & 1.26 & 0.27 & 2.72 & 0.0065 \\
\hline
\end{tabular}




\begin{tabular}{|c|c|c|c|c|c|c|c|c|c|}
\hline Meta-analysis & Moderator & Level & $k$ & SMD & $-95 \% \mathrm{Cl}$ & $+95 \% \mathrm{Cl}$ & SE & Z-score & $P$ value \\
\hline \multirow[t]{13}{*}{ Health outcomes } & Overall effect & - & 3 & -0.03 & -0.11 & 0.05 & 0.04 & -0.75 & 0.4519 \\
\hline & \multirow[t]{2}{*}{ Risk of bias } & High risk of bias & 1 & -0.04 & -0.22 & 0.13 & 0.09 & -0.45 & 0.6497 \\
\hline & & Low risk of bias & 2 & -0.03 & -0.12 & 0.06 & 0.05 & -0.61 & 0.5406 \\
\hline & \multirow[t]{2}{*}{ Study design } & RCT & 3 & -0.03 & -0.11 & 0.05 & 0.04 & -0.75 & 0.4519 \\
\hline & & Non-RCT & 0 & - & - & - & - & - & - \\
\hline & \multirow[t]{2}{*}{ Intervention length } & Up to 8 weeks & 0 & - & - & - & - & - & - \\
\hline & & More than 8 weeks & 3 & -0.03 & -0.11 & 0.05 & 0.04 & -0.75 & 0.4519 \\
\hline & \multirow[t]{2}{*}{ Number of sessions } & One-off session & 0 & - & - & - & - & - & - \\
\hline & & More than one session & 3 & -0.03 & -0.11 & 0.05 & 0.04 & -0.75 & 0.4519 \\
\hline & \multirow[t]{2}{*}{ School type } & Preschool & 0 & - & - & - & - & - & - \\
\hline & & Elementary and over & 3 & -0.03 & -0.11 & 0.05 & 0.04 & -0.75 & 0.4519 \\
\hline & \multirow[t]{2}{*}{ Intervention delivery } & Existing classroom teacher & 2 & -0.03 & -0.12 & 0.06 & 0.04 & -0.61 & 0.5409 \\
\hline & & Recruited personnel & 1 & -0.05 & -0.25 & 0.15 & 0.10 & -0.48 & 0.631 \\
\hline \multirow[t]{13}{*}{ Cognitive outcomes } & Overall effect & - & 3 & 0.01 & -0.23 & 0.25 & 0.12 & 0.09 & 0.9294 \\
\hline & \multirow[t]{2}{*}{ Risk of bias } & High risk of bias & 2 & 0.11 & -0.22 & 0.44 & 0.17 & 0.65 & 0.5126 \\
\hline & & Low risk of bias & 1 & -0.16 & -0.60 & 0.29 & 0.23 & -0.69 & 0.4901 \\
\hline & \multirow[t]{2}{*}{ Study design } & RCT & 3 & 0.01 & -0.23 & 0.25 & 0.12 & 0.09 & 0.9294 \\
\hline & & Non-RCT & 0 & - & - & - & - & - & - \\
\hline & \multirow[t]{2}{*}{ Intervention length } & Up to 8 weeks & 0 & - & - & - & - & - & - \\
\hline & & More than 8 weeks & 3 & 0.01 & -0.23 & 0.25 & 0.12 & 0.09 & 0.9294 \\
\hline & \multirow[t]{2}{*}{ Number of sessions } & One-off session & 0 & - & - & - & - & - & - \\
\hline & & More than one session & 3 & 0.01 & -0.23 & 0.25 & 0.12 & 0.09 & 0.9294 \\
\hline & \multirow[t]{2}{*}{ School type } & Preschool & 0 & - & - & - & - & - & - \\
\hline & & Elementary and over & 3 & 0.01 & -0.23 & 0.25 & 0.12 & 0.09 & 0.9294 \\
\hline & \multirow[t]{2}{*}{ Intervention delivery } & Existing classroom teacher & 3 & 0.01 & -0.23 & 0.25 & 0.12 & 0.09 & 0.9294 \\
\hline & & Recruited personnel & 0 & - & - & - & - & - & - \\
\hline
\end{tabular}

physically active lessons on multiple occasions, total weekly intervention duration ranged from $10 \min ^{55}$ to $180 \mathrm{~min}$ a day. ${ }^{56}$ Only two studies were explicitly based on theory, namely the COM-B model of behaviour change which posits an individual's capability, opportunity and motivation as key influences on behaviour. ${ }^{18}{ }^{37}$ One study presented a logic model of how it's physically active lesson intervention may impact student's sedentary behaviour and educational outcomes. ${ }^{47}$ Thirty-three out of 42 studies reported interventions as delivered by existing classroom teachers (table 1), with the remainder delivered by recruited personnel of teachers or researchers.

Sample sizes ranged from $n=21^{49}$ to $n=2493,{ }^{53}$ with a total of $n=12663$ across all included studies. Participant ages ranged from $3^{45} 57-59$ to 14 years old..$^{35}$ Boys made up between $31.5 \% \%^{57}$ and $59.4 \% \%^{56}$ of total study participants. Among the 12 studies reported participants' ethnicity, ethnic minorities represented between $7.1 \%{ }^{60}$ and $100 \%{ }^{5758}$ of these study samples. Seven studies reported free or reduced school meals status as a measure of socioeconomic status, with up to $94 \%{ }^{61}$ of participants receiving these.

\section{Outcome assessments}

Physical activity outcomes were assessed in 24 studies, ${ }^{17-19} 36373944474851-55$ 57-66 with 21 assessing lesson-time activity ${ }^{17-1936373944474851-5557-5961-6366}$ and 14 assessing overall physical activity ${ }^{17} 183747485153545960$ 63-66 (online supplementary file 1). Fifteen studies assessed activity with accelerometers, ${ }^{17-19}$ $3747485153-555962636667$ eight with observations ${ }^{18} 39445457-5961$ (six of these using the System of Observing Fitness Instruction Time momentary assessment tool, ${ }^{68}$ two with pedometers ${ }^{64} 65$ and two with questionnaires. ${ }^{36}{ }^{60}$ Educational outcomes were assessed in 36 studies, ${ }^{17-19} 353839$ 42-52 54-58 60-64 66 69-75 with 28 assessing overall education such as academic achievement ${ }^{1935} 3842-4648495254-5860-636669-75$ and 8 assessing lesson-time educational outcomes of observed time-on-task. ${ }^{171839} 4750516676$ Cognitive outcomes such as fluid intelligence were assessed in four studies. ${ }^{39} 4060626472$ Health outcomes were assessed in seven studies, ${ }^{36} 404144546375$ with six assessing BMI ${ }^{364144546375}$ and five assessing cardiovascular fitness ${ }^{40} 41446375$ (online supplementary file 1).

\section{Behaviour change techniques used in interventions}

Interventions contained an average of $3.9 \mathrm{BCTs}$, with a range between 0 and 12 (online supplementary file 2). The most frequently coded BCTs were Instruction on how to perform the behaviour (BCT 4.1: $n=31 / 42$ ), Adding objects to the environment (BCT 12.5: $\mathrm{n}=27 / 42$ ), Self-monitoring of behaviour (BCT 2.3: $n=16 / 42$ and Feedback on behaviour (BCT 2.2: $n=10 / 42$ ). Objects added to the classroom were low-cost, such as a USB stick of pre-prepared physically active lessons ${ }^{18}$ or an audio CD and $\mathrm{CD}$ player. ${ }^{65}$

\section{Risk of bias within studies}

All 42 studies were assessed to be high risk on at least one domain, with 25/42 having additional high risk of bias in at least one other domain (figure 3). Eight studies had high risk of random sequence generation selection bias, with the majority of studies reporting appropriate methods to their randomisation procedure (low risk of bias; $n=13 / 42$ ) or not describing these processes (unclear risk of bias; $n=21 / 42$ ). Allocation concealment selection bias was unclearly reported in 39/42 studies. All 


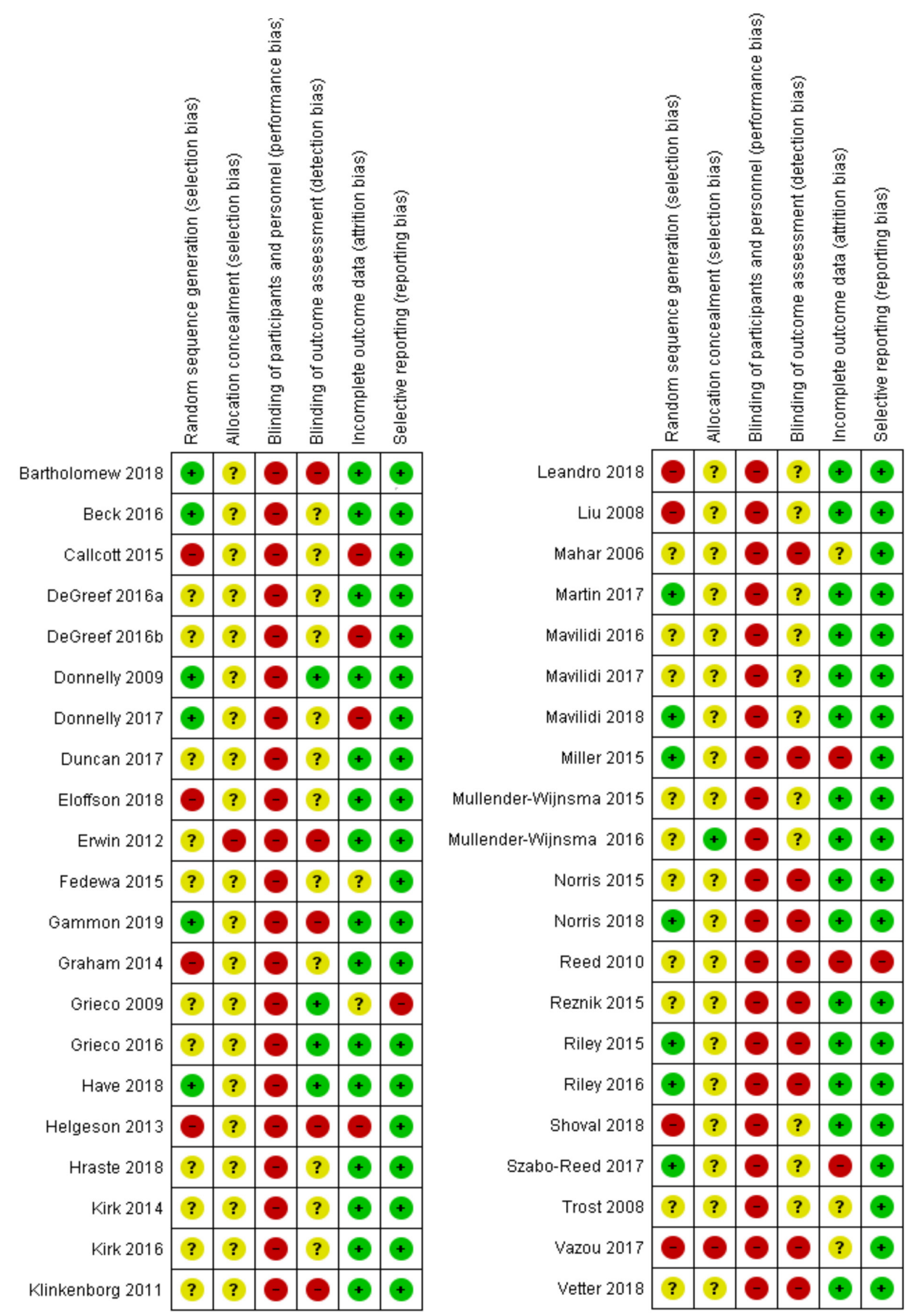

Note: '+' denotes low risk of bias, '?' denotes unclear risk of bias and '-' denotes high risk of bias.

Figure 3 Risk of bias assessment of identified physically active lesson studies.

studies had high risk of performance bias, as blinding was not attempted in either the people delivering the intervention or in pupils receiving the intervention. Fifteen studies had high levels of detection bias, whereby outcome assessors were not blinded. Seven studies had high attrition bias, losing high proportions of their sample during the intervention, such as multiple schools dropping out for unclear reasons. Forty out of 42 studies were judged at low risk of selective reporting bias. Overall, the risk of bias rating across all domains was relatively even between unclear (33.45\%), low risk (33.1\%) and high risk ratings $(33.45 \%)$.

\section{Intervention effects on outcomes}

We conducted six meta-analyses : (1) lesson-time PA, (2) overall PA, (3) lesson-time educational outcomes, (4) overall educational outcomes, (5) health and (6) cognitive outcomes. The reasons for exclusion from meta-analyses were insufficient data from studies and authors not responding to requests for data (25 comparisons from 10 studies). See figures 4-9 for forest plots of the six meta-analyses. See table 1 for overall effects and subgroup effects of all four meta-analyses, whereby ' $k$ ' refers to number of studies, with studies being eligible for inclusion across all six meta-analyses. An overview of outcomes in 


\section{Lesson-Time Physical Activity}

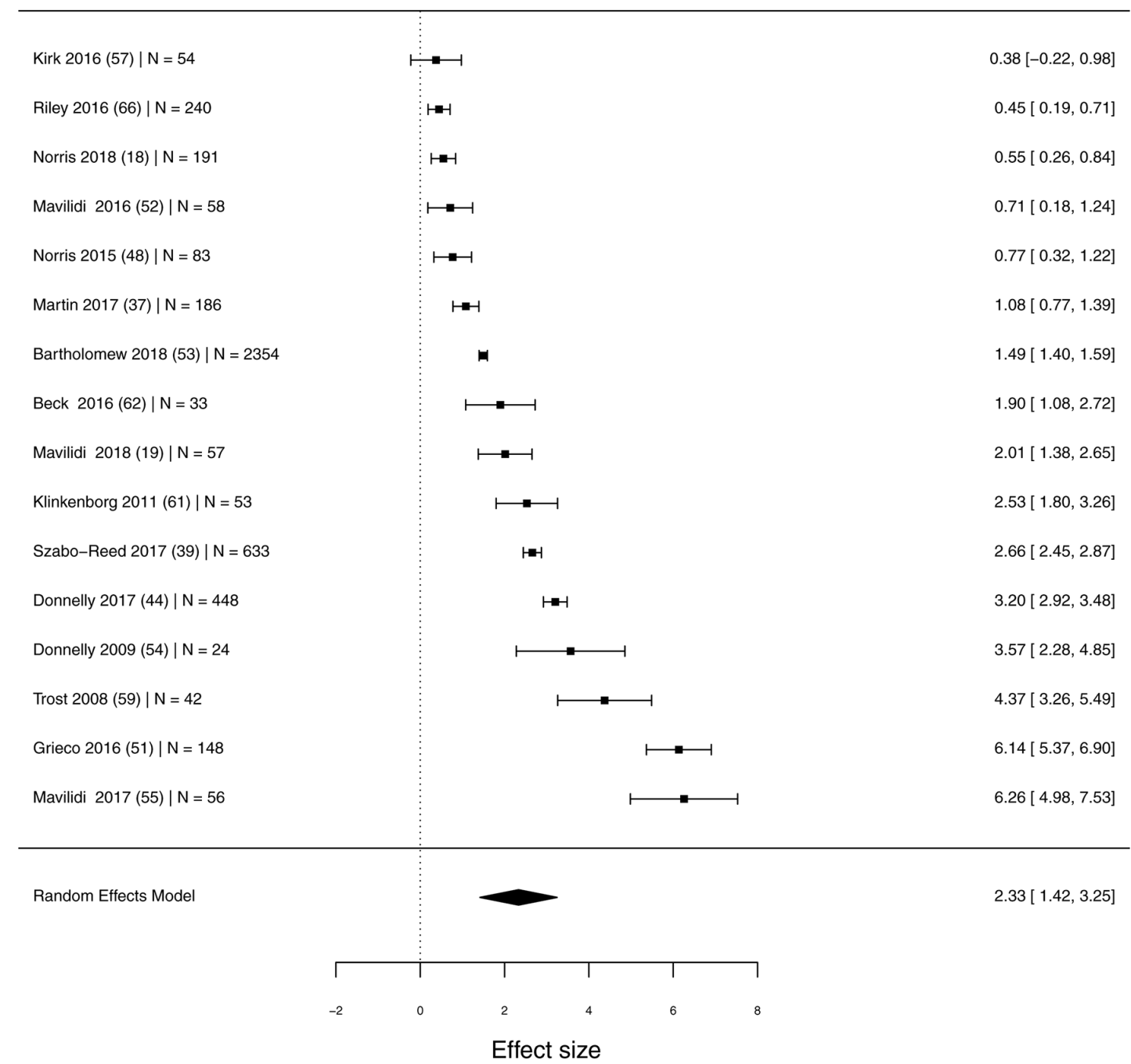

Figure 4 Forest plot of the effect of physically active lessons on lesson-time physical activity.

included studies and their moderator coding is in online supplementary file 3 .

\section{Lesson-time physical activity}

Data from 16 studies assessing lesson-time physical activity were included $\left(\mathrm{N}_{\text {total }}=4660\right)$. A random-effects model was applied to the data, as supported by the Q-test of heterogeneity $(Q(15)=626.79, \mathrm{p}<0.0001)$. The meta-analysis showed a significant, large, positive impact of physically active lessons on lesson-time physical activity compared with control lessons (standardised mean difference $(\mathrm{SMD})=2.33$, 95\% CI 1.42 to $3.25, \mathrm{p}<0.0001$; figure 4). The trim-and-fill method used to investigate publication bias suggested there was no publication bias, meaning the estimated number of missing studies is zero. The leave-one-out method used to test the robustness of the findings showed no material change in significance levels or in overall effect size. All moderator tests showed non-significant results (all $p$ 's $>0.18$; see table 1 for subgroup effects).

\section{Overall physical activity}

Data from 10 studies assessing overall physical activity were included $\left(\mathrm{N}_{\text {total }}=4679\right)$. A random-effects model was applied to the data, a decision that was supported by the Q-test of heterogeneity $(Q(9)=98.67, p<0.0001)$. Physically active lessons showed a non-significant, moderate increase in overall physical activity $(\mathrm{SMD}=0.49,95 \% \mathrm{CI}-0.11$ to $1.10, \mathrm{p}=0.11)$. We detected no publication bias.

However, the iterative process of the leave-one-out method revealed that this non-significant effect was driven by two influential studies. ${ }^{47}$ First, the Trost paper has a very large effect size $(\mathrm{SMD}=3.71,95 \% \mathrm{CI} 2.72$ to 4.71$)$ which, in addition to inflating the overall effect size, substantially widened the $95 \% \mathrm{CI}$ of the overall effect. Second, the Gammon paper reported less vigorous physical activity in the follow-up of the intervention group compared with control groups ( $3.0 \mathrm{~min}$ vs $4.7 \mathrm{~min}$ ), which was extracted following the pre-planned strategy. However, mean difference scores from baseline to post-intervention offered crucial insightful, as the control group decreased vigorous activity by $0.8 \mathrm{~min}$ compared with $0.1 \mathrm{~min}$ in the intervention group. ${ }^{47}$ The results of our leave-one-out method analyses suggested the possibility for misleading results: for this reason we decided to remove the Gammon paper from the subsequent overall physical activity meta-analysis. When both Trost and Gammon papers were excluded from the sample (leaving $\mathrm{N}_{\text {total }}=4467$ ), the overall 


\section{Overall Physical Activity}

Author, year, (reference number), sample size

Effect size, $[95 \% \mathrm{Cl}]$

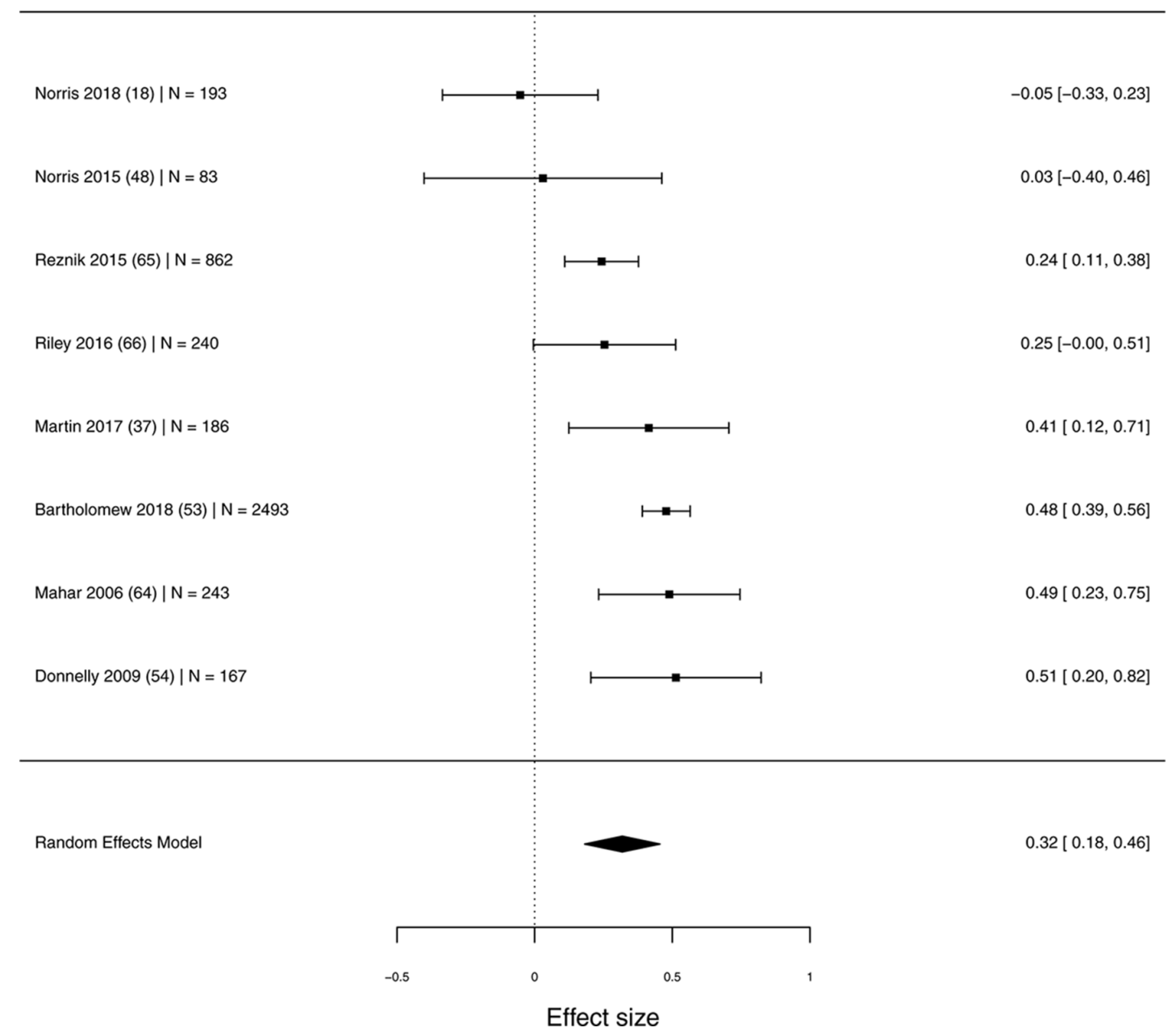

Figure 5 Forest plot of the effect of physically active lessons on overall physical activity. Trost 2008 and Gammon 2019 were removed from final meta-analysis using the leave-one-out method.

effect size changed from a medium, non-significant effect to a small, yet significant effect $(\mathrm{SMD}=0.32,95 \%$ CI 0.18 to 0.46 , $\mathrm{p}<0.0001$; figure 5). All moderator tests showed non-significant results (all $p$ 's $>0.25$; see table 1 for subgroup effects).

\section{Lesson-time educational outcomes}

Data from seven studies assessing lesson-time educational outcomes of time-on-task were included $\left(\mathrm{N}_{\text {total }}=1416\right)$. A random-effects model was fitted to the data, with this decision supported by a $\mathrm{Q}$-test $(Q(5)=67.74, \mathrm{p}<0.0001)$. There was a large, significant effect of physically active lessons on lessontime educational outcomes $(\mathrm{SMD}=0.81,95 \% \mathrm{CI} 0.47$ to 1.14 , $\mathrm{p}<0.0001$; figure 6 ). There was no sign of publication bias and the leave-one-out sensitivity analysis did not reveal any studies to influence effects.

Intervention length was a significant moderator $(\mathrm{Q}(1)=5.71$, $\mathrm{p}=0.017$ ), with interventions shorter than 8 weeks showing larger effects $(\mathrm{SMD}=0.95,95 \% \mathrm{CI} 0.68$ to 1.21$)$ than interventions longer than 8 weeks $(\mathrm{SMD}=0.20,95 \% \mathrm{CI}-0.35$ to $0.75)$. This difference needs to be interpreted with caution as the subgroup of interventions longer than 8 weeks consists only of a single study. All other moderators were not significant (all $p$ 's $>0.31$; see table 1 for subgroup effects).
Overall educational outcomes

Twenty-five studies assessed educational outcomes $\left(\mathrm{N}_{\text {total }}=3214\right)$. A random-effects model was applied to the data, again supported by a significant Q-test of heterogeneity $(Q \quad(24)=136.95$, $\mathrm{p}<0.0001)$. Physically active lessons resulted in a small improvement in overall educational outcomes $(\mathrm{SMD}=0.36,95 \% \mathrm{CI} 0.09$ to $0.63, \mathrm{p}<0.01$; figure 7 ). There was no sign of publication bias and the leave-one-out sensitivity analysis did not reveal any studies to influence effects. All moderator tests showed non-significant results (all $p$ 's $>0.09$; see table 1 for subgroup effects).

\section{Health outcomes}

Data from three studies assessing health outcomes were included $\left(\mathrm{N}_{\text {total }}=2365\right)$, with data from two studies assessing BMI ${ }^{4154}$ and one assessing fitness. ${ }^{40}$ While the Q-test of heterogeneity was not significant $(Q(2)=0.07, p=0.97)$, a random-effects models was applied to the data based on the differences in outcome measures across the three studies. There was no effect of physically active lessons on health outcomes $(\mathrm{SMD}=-0.03,95 \% \mathrm{CI}$ -0.11 to $0.05, \mathrm{p}=0.45$; figure 8 ). There was no sign of publication bias and the leave-one-out sensitivity analysis did not reveal any studies to influence effects. All moderator tests showed 


\section{Lesson-Time Educational Outcomes}

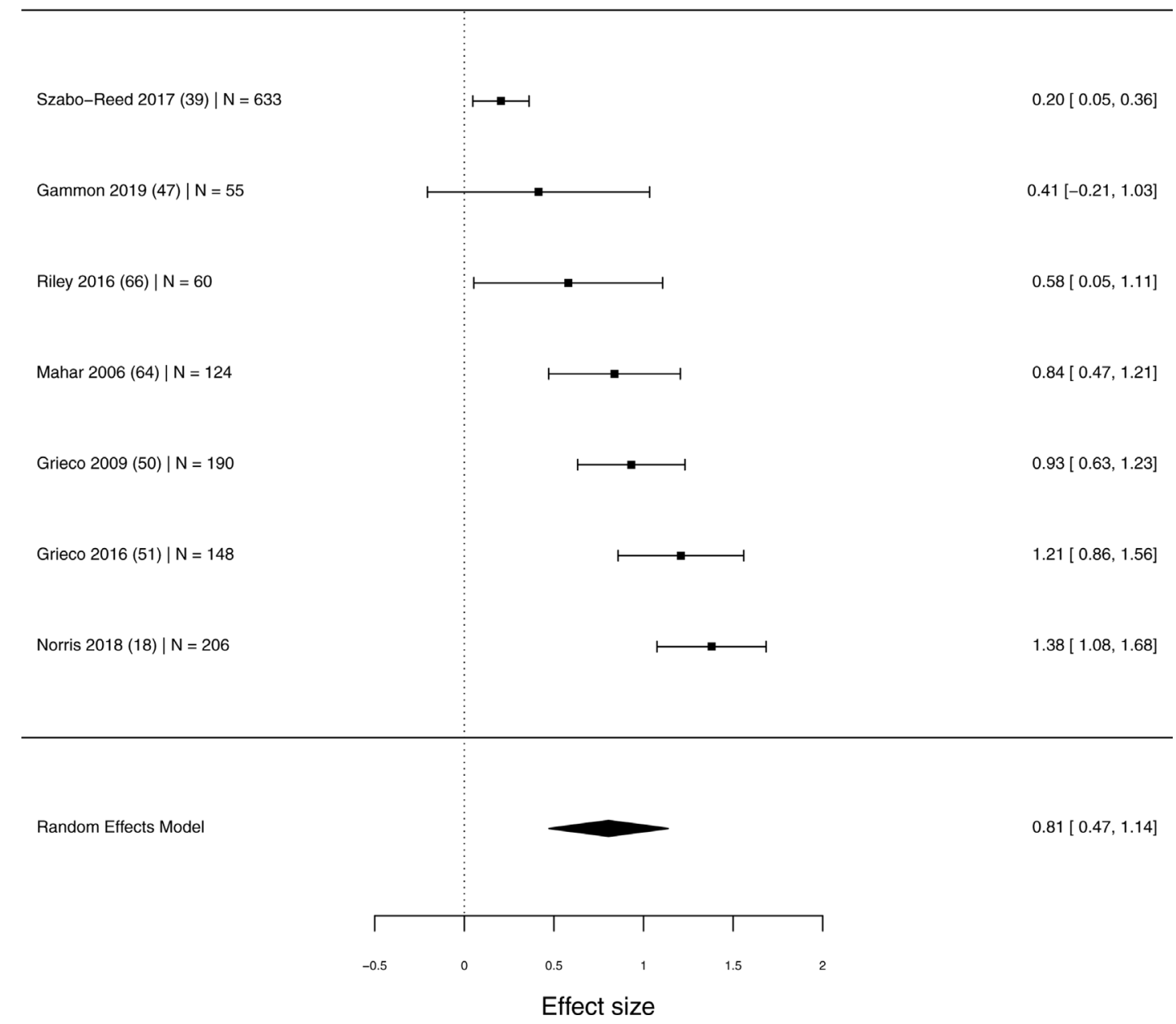

Figure 6 Forest plot of the effect of physically active lessons on lesson-time educational outcomes.

non-significant results (all $p$ 's $>0.84$; see table 1 for subgroup effects).

\section{Cognitive outcomes}

Data from three studies assessing cognitive outcomes were included $\left(\mathrm{N}_{\text {total }}=1100\right)$, with data from two studies assessing fluid intelligence ${ }^{6072}$ and one assessing executive functions. ${ }^{40}$ While the Q-test of heterogeneity $(Q(2)=5.98, p=0.05)$ was marginally significant, a random-effects model was applied to the data due to the differences in outcome variables in individual studies. There was no effect of physically active lessons on cognitive outcomes $(\mathrm{SMD}=0.01,95 \% \mathrm{CI}-0.23$ to $0.25, \mathrm{p}=0.93$; figure 9). There was no sign of publication bias and the leaveone-out sensitivity analysis did not reveal any studies to influence effects. All moderator tests showed non-significant results (all $p$ 's $=0.34$; see table 1 for subgroup effects).

\section{DISCUSSION}

This systematic review and meta-analysis identified 42 studies comparing physically active lessons to typical teaching control groups. A body of primarily RCT evidence, showed that physically active lessons produced statistically significant increases in lesson-time and overall physical activity. A mixed set of randomised and non randomised studies showed improvements in lesson-time and overall educational outcomes. A small body of RCT evidence showed that no effect on cognitive or health outcomes.

Physically active lessons resulted in large increases in lessontime physical activity, accompanied by small, significant increases in overall activity. The smaller increases in overall compared with lesson-time activity may indicate a potential compensation mechanism, whereby children exert lower levels of activity after active lessons to compensate for their earlier increased exertion. ${ }^{77}$ An alternative explanation may be that physically active lessons as an 'expansion' of new physical activity opportunities may be insufficient alone to lead to larger increases in overall activity. ${ }^{78}$ The combination of expansion activity opportunities with the 'extension' of new activity opportunities and 'enhancement' of wider activity strategies may be needed in schools for larger activity benefits. ${ }^{78}$ Overall, these physical activity findings are consistent with previous systematic reviews that qualitatively synthesised results of physically active lessons. ${ }^{152021}$ However, this review's findings contrast with a meta-analysis of 11 classroom-based activity interventions of varying content such as active breaks and physically active lessons, which found no effect on observed activity levels. ${ }^{22}$ Conducting meta-analyses with strict inclusion criteria to specific intervention characteristics may decrease heterogeneity of interventions and reveal a more accurate estimate of effects. 


\section{Overall Educational Outcomes}

Author, year, (reference number), sample size

Effect size, $[95 \% \mathrm{Cl}]$

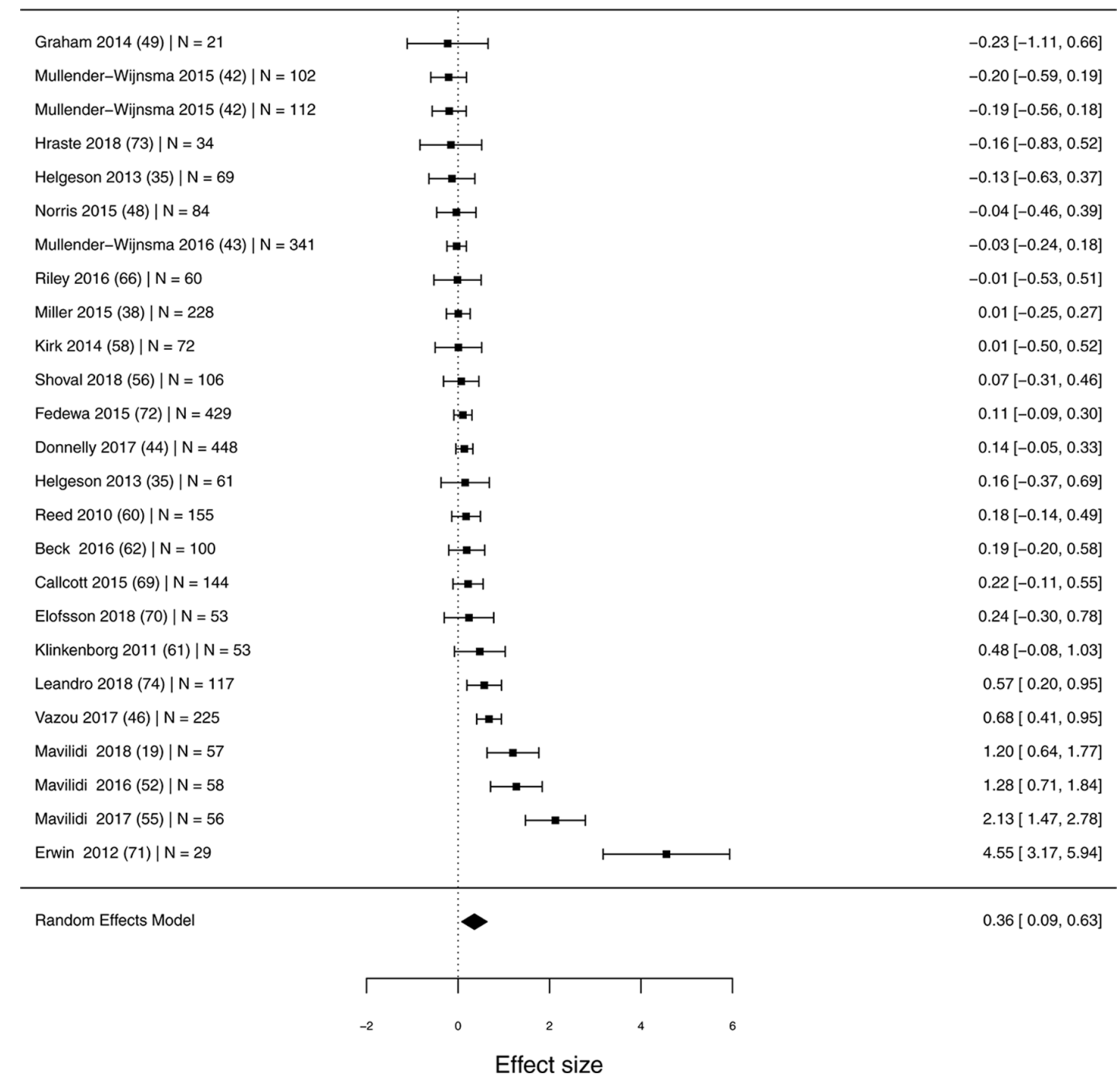

Figure 7 Forest plot of the effect of physically active lessons on overall educational outcomes.

In contrast to the findings of the first systematic review of physically active lessons in $2015,{ }^{20}$ physical activity measurement here was predominantly via objective accelerometers and pedometers, rather than questionnaires or observations. However, the duration of assessment varied greatly, with some studies assessing school-time activity only and others assessing full weekday and weekend day activity. ${ }^{18} 54$ Between three to seven full days of objective assessment may be necessary to assess change in children's habitual activity levels, ${ }^{79}$ however the majority of included studies fell short of this. There was also a consistent lack of physical activity reporting by key demographics, preventing assessment of whether active lessons could improve activity in certain groups at risk of lower activity levels, such as girls and ethnic minorities. ${ }^{1}$

Increases in physical activity were not accompanied by improved health outcomes, as assessed by a small meta-analysis of three studies assessing BMI and cardiovascular fitness. ${ }^{40} 4154$ This lack of effect was seen despite the included studies featuring long intervention periods of between 22 weeks to 3 years, relatively large active lesson doses compared with other studies of around $90 \mathrm{~min}$ a week and large sample sizes. As such, the lack of effect in this small number of relatively robust studies may suggest that physically active lessons are not sufficient to improve children's BMI and fitness. BMI is a limited measure of health risk in children, skinfold thickness and waist circumference $^{80}$ are far more informative.

We report a positive impact of physically active lessons on education on lesson-time and overall outcomes. This concurs with the meta-analysis of classroom-based physical activity interventions, which found significant increases to both timeon-task and academic achievement. ${ }^{22}$ Increased time-on-task as a lesson educational outcome may have prompted pupils to pay greater attention to the educational content delivered, translating to knock-on benefits to overall education in the forms of academic achievement. ${ }^{51}$ The meta-analysis of available data from three studies in this review found no evidence of benefits to cognitive outcomes of fluid intelligence and executive functions: important precursors to academic outcomes. ${ }^{81}$ There was a lack of theoretical basis evident in included studies as to why active learning may facilitate educational improvements. Studies commonly cited previous experimental research indicating learning capacity to increase following acute, intense aerobic 
Health Outcomes

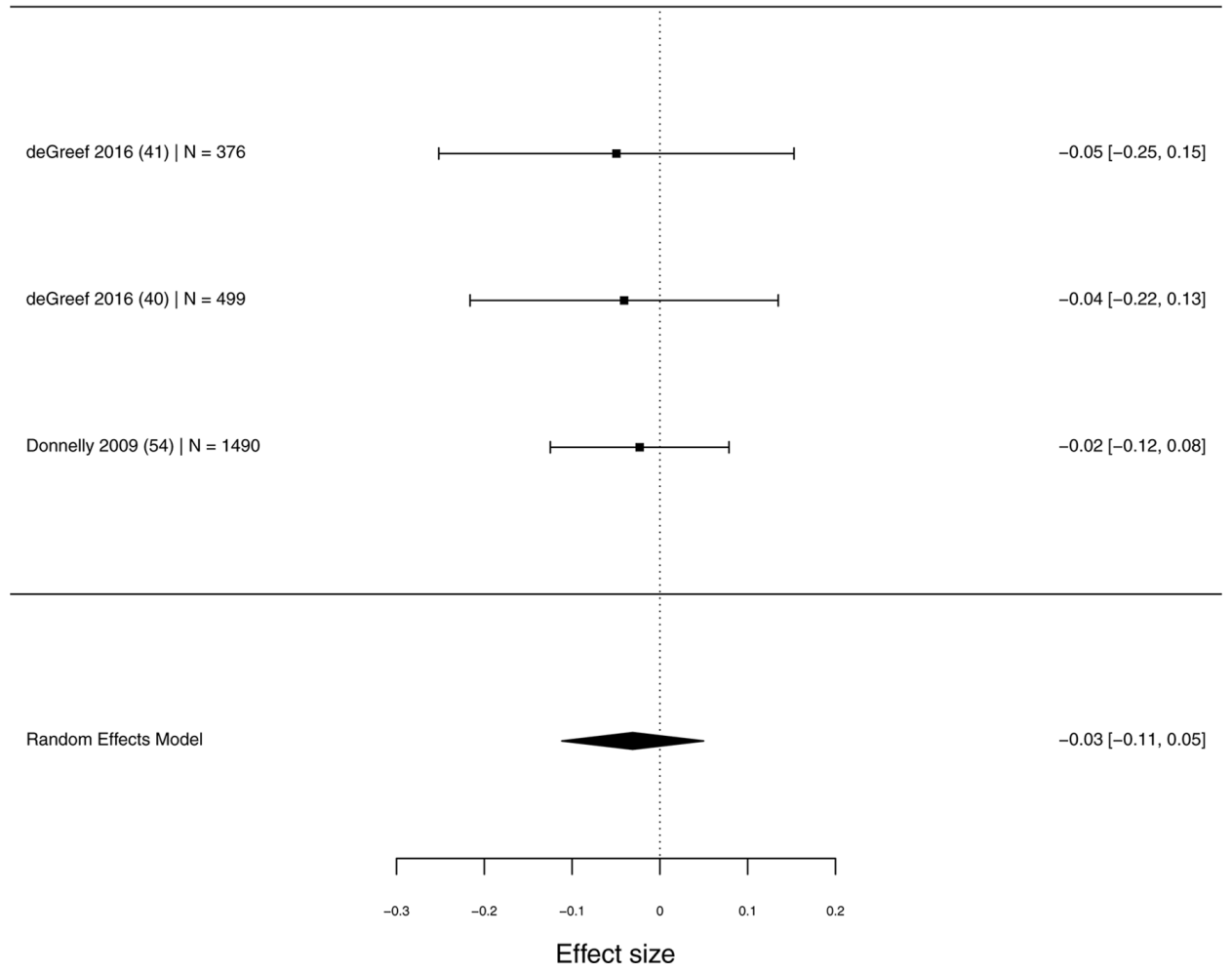

Figure 8 Forest plot of the effect of physically active lessons on health outcomes.

exercise as rationale for their interventions ${ }^{82}$ but typically did not extend their rationale to less intense school-based activity nor addressing why knock-on effects may be seen in educational settings.

\section{Strengths and limitations of identified studies}

More robust study designs (more RCTs) of physically active lessons have been published since the first review of physically active lessons in $2015,{ }^{20}$ as shown by the 42 controlled studies identified here. Longer intervention periods are also apparent, with half of all identified studies having a duration of over 12 weeks, recommended for school-based health interventions. ${ }^{12}$ However, few studies had a follow-up period beyond the intervention period. This led to our meta-analyses being restricted to the earliest follow-up only, meaning we could not test whether physically active interventions have a lasting were associated with benefits beyond their initial implementation period. Although sample sizes have increased ${ }^{44} 53$ since the first review of physically active lessons in $2015,{ }^{20}$ these samples remain relatively white, ${ }^{83}$ with a limited number of studies targeting ethnic minority or deprived populations. 575861

High risk of bias was observed in the majority of identified studies. A lack of teachers and pupil blinding in all studies, and a lack of blinding for outcome assessors in one-third of studies show that key methodological issues still persist in the area. ${ }^{20}$ Such notable bias concurs with other reviews, such as Watson's review of classroom-based activity interventions which identified 36/39 studies to have moderate or weak quality ${ }^{22}$ using the Effective Public Health Practice Project tool. ${ }^{84}$ Findings of this review should hence be interpreted with caution, as most studies had methodological weaknesses.

Instances of authors reporting study outcomes from one physically active lesson intervention across multiple papers were apparent. Arguably this restricts teachers', researchers' and policymakers' access to the full range of available findings for a given intervention, with these papers also often in multiple pay-walled journals. Readers of one study will hence not receive full details on the methods and results of a given intervention, limiting the ability to build on the research and limiting the likelihood of full, real-world implementation. ${ }^{85}$

The majority of studies did not integrate teachers and schools into the development of physically active lessons, instead providing fairly rigid, pre-developed programmes. Lack of teacher involvement in intervention development can lead to teachers' concerns not been addressed, lower motivation for them to deliver content and lower levels of delivery and fidelity as a consequence. ${ }^{86-88}$ This may be evidenced in this review by moderator analyses identifying lower effects on overall educational outcomes for interventions delivered by existing classroom teachers compared to recruited personnel. More inclusive practice is seen in the study of Gammon ${ }^{47}$ which focused on the provision of in-depth skills training for physically active teaching, designed to empower teachers to deliver active teaching to high school pupils across subjects. Effective teacher-led approaches are required to allow more sustainable interventions in terms of cost and practicality, compared with recruiting external personnel. More in-depth approaches to physically active lessons such as the provision of in-depth teacher training or co-creation techniques are arguably required to facilitate longer-lasting provision of active lessons. ${ }^{86} 89$ 


\section{Cognitive Outcomes}

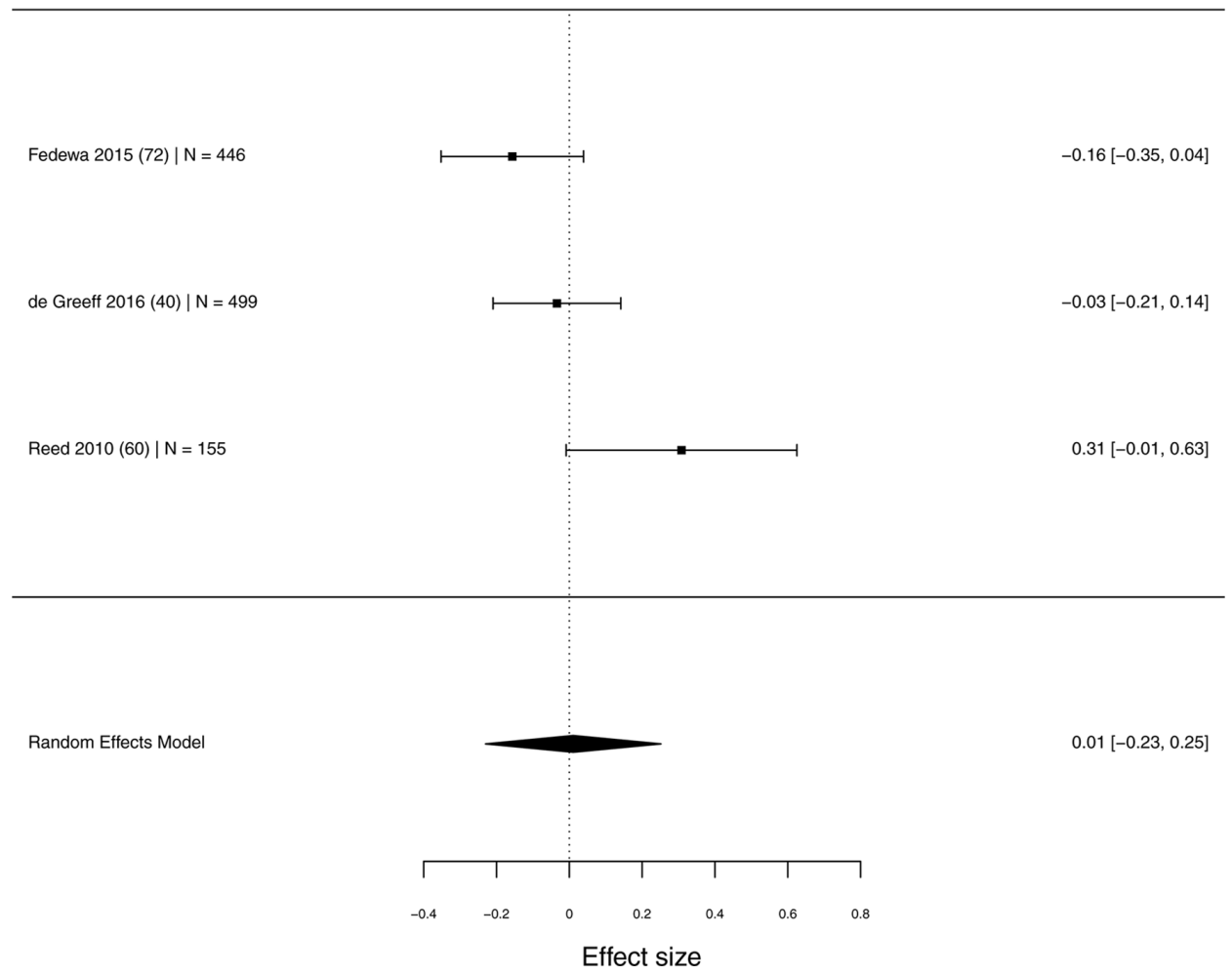

Figure 9 Forest plot of the effect of physically active lessons on cognitive outcomes.

A lack of theory behind the development of physically active lesson interventions also remains, with only two studies evidencing a clear theoretical basis. ${ }^{18} 37$ Studies also generally did not specify hypothesised pathways of how active lessons may benefit activity, health or educational outcomes. Similar to a related logic model charting the relationship between children's physical activity, cognitive and mental health outcomes ${ }^{9}$; one identified study in our review provided a logic model outlining the relationship between physically active lessons and educational outcomes. ${ }^{47}$ This logic model first posits the provision of teacher training in active learning principles to increase teacher's confidence and motivation to deliver. Subsequent teacher implementation of active lessons is posited to reduce pupil sedentary behaviour and increase their time-on-task during active lessons, with consequent improvements to pupils lesson enjoyment, engagement and academic performance. ${ }^{47}$ This lack of theory and pathway hypotheses inhibits our ability to assess the mechanisms $^{90}$ of why identified positive effects exist for physically active lessons.

Finally, only a small minority (3/42) of included studies were carried out in middle and high school settings, which precludes generalising the review findings outside preschool and elementary schools.

\section{Strengths and limitations of this review}

This review is the first to meta-analyse the impact of physically active lesson interventions. Strengths of this review include its use of double-coding for all extracted data and its inclusion of controlled studies from single-component interventions to isolate the effects of physically active lessons compared with typical teaching. Limitations of this review include its lack of process evaluation reports of physically active lesson interventions $^{86}$ and its exclusive inclusion of English language studies. Studies assessing active breaks were excluded from this review, although it may be that breaks embedded educational content but were not explicitly described to do so. Additionally, this review focused on general school populations only, meaning that effects on children with Special Educational Needs or obesity were not assessed.

\section{Areas for future research}

Gaps in the evidence identified in this review suggest a need for research in high schools, longer intervention periods with larger doses of physically active lessons and more comprehensive reporting of health outcomes. A theoretical basis to physically active lesson intervention is also required, to allow assessment of the mechanisms facilitating behaviour change. ${ }^{90}$ Facilitation of physically active lessons in the real-world would also be aided by complete reporting of interventions and outcomes in singular studies and co-creation of interventions with schools. ${ }^{89}$ More studies in secondary school settings are also needed.

\section{CONCLUSIONS}

Based on a body of evidence from controlled trials, this first meta-analysis of physically active lessons found them to significantly increase pupils' physical activity and improve educational outcomes. The relatively few studies with cognition or BMI and fitness outcomes showed no effects. This review shows that physically active lessons can be a useful addition into current 
curriculum with plausible positive impact on physical activity levels and academic outcomes. Future studies should adhere to robust RCT designs, include more secondary school pupils and test longer follow-up periods, greater doses of physically active lessons and a more diverse range of health outcomes.

Summary box

What is already known?

- Physically active lessons combine physical activity with educational content in the school classroom.

What are the new findings?

- Physically active lessons significantly increase lesson-time physical activity and overall physical activity.

- Physically active lessons significantly increase lesson-time education such as time-on-task and overall education such as academic achievement, although a substantial part of such studies involved non-randomised designs.

- A small body of randomised controlled trial evidence showed that there were no effects on cognitive or health outcomes.

- The large majority of reviewed studies took place in elementary and pre-elementary school settings.

Contributors All authors approved the review protocol. EN performed searches. EN, AD and TvS performed screening. EN, AD and TvS performed data extraction and risk of bias assessment. EN and TVS wrote the first draft, with all authors contributing to drafts and approving the final version of the manuscript.

Funding The authors have not declared a specific grant for this research from any funding agency in the public, commercial or not-for-profit sectors.

Competing interests None declared.

Patient consent for publication Not required.

Provenance and peer review Not commissioned; externally peer reviewed.

ORCID iDs

Emma Norris http://orcid.org/0000-0002-9957-4025

Tommy van Steen http://orcid.org/0000-0002-5805-4664

Artur Direito http://orcid.org/0000-0002-2236-8506

Emmanuel Stamatakis http://orcid.org/0000-0001-7323-3225

\section{REFERENCES}

1 Griffiths LJ, Cortina-Borja M, Sera F, et al. How active are our children? findings from the millennium cohort study. BMJ Open 2013;3:e002893.

2 Hallal PC, Andersen LB, Bull FC, et al. Global physical activity levels: surveillance progress, pitfalls, and prospects. The Lancet 2012;380:247-57.

3 World Health Organisation. Global recommendations on physical activity for health Geneva, Switzerland: World Health Organisation, 2010.

4 Bailey DP, Fairclough SJ, Savory LA, et al. Accelerometry-assessed sedentary behaviour and physical activity levels during the segmented school day in 10-14-year-old children: the happy study. Eur J Pediatr 2012;171:1805-13.

5 Mantjes JA, Jones AP, Corder K, et al. School related factors and 1yr change in physical activity amongst 9-11 year old English schoolchildren. Int I Behav Nutr Phys Act 2012;9.

6 Cesa CC, Sbruzzi G, Ribeiro RA, et al. Physical activity and cardiovascular risk factors in children: meta-analysis of randomized clinical trials. Prev Med 2014:69:54-62.

7 Hillman CH, Erickson KI, Kramer AF. Be smart, exercise your heart: exercise effects on brain and cognition. Nat Rev Neurosci 2008;9:58-65.

8 Biddle SJH, Asare M. Physical activity and mental health in children and adolescents: a review of reviews. Br J Sports Med 2011;45:886-95.

9 Lubans D, Richards J, Hillman C, et al. Physical activity for cognitive and mental health in youth: a systematic review of mechanisms. Pediatrics 2016;138:e20161642.

10 HM Government. Childhood obesity: a plan for action. London: HM Government, 2016.

11. Donnelly JE, Lambourne K. Classroom-Based physical activity, cognition, and academic achievement. Prev Med 2011;52(Suppl 1):S36-S42.

12 Dobbins M, Husson H, DeCorby K, et al. School-Based physical activity programs for promoting physical activity and fitness in children and adolescents aged 6 to 18 . Cochrane Database Syst Rev 2013;19.

13 Norris E, Shelton N, Dunsmuir S, et al. Teacher and pupil perspectives on the use of virtual field trips as physically active lessons. BMC Res Notes 2015;8:719.
14 Quarmby T, Daly-Smith A, Kime N. 'You get some very archaic ideas of what teaching is...': primary school teachers' perceptions of the barriers to physically active lessons. Education 2018:1-14.

15 Daly-Smith AJ, Zwolinsky S, McKenna J, et al. Systematic review of acute physically active learning and classroom movement breaks on children's physical activity, cognition, academic performance and classroom behaviour: understanding critical design features. BMJ Open Sport Exerc Med 2018;4:e000341.

16. Bartholomew JB, Jowers EM. Physically active academic lessons in elementary children. Prev Med 2011;52(Suppl 1):S51-S54.

17 Riley N, Lubans DR, Morgan PJ, et al. Outcomes and process evaluation of a programme integrating physical activity into the primary school mathematics curriculum: the easy minds pilot randomised controlled trial. J Sci Med Sport 2015;18:656-61.

18 Norris E, Dunsmuir S, Duke-Williams O, et al. Physically Active Lessons Improve Lesson Activity and On-Task Behavior: A Cluster-Randomized Controlled Trial of the "Virtual Traveller" Intervention. Health Educ Behav 2018;45:945-56.

19 Mavilidi M-F, Okely A, Chandler P, et al. Immediate and delayed effects of integrating physical activity into preschool children's learning of numeracy skills. J Exp Child Psychol 2018;166:502-19.

20 Norris E, Shelton N, Dunsmuir S, et al. Physically active lessons as physical activity and educational interventions: a systematic review of methods and results. Prev Med 2015;72:116-25

21 Martin R, Murtagh EM. Effect of active lessons on physical activity, academic, and health outcomes: a systematic review. Res Q Exerc Sport 2017;88:149-68.

22 Watson A, Timperio A, Brown H, et al. Effect of classroom-based physical activity interventions on academic and physical activity outcomes: a systematic review and meta-analysis. Int J Behav Nutr Phys Act 2017;14.

23 Owen KB, Parker PD, Van Zanden B, et al. Physical activity and school engagement in youth: a systematic review and meta-analysis. Educ Psychol 2016;51:129-45.

24 Singh AS, Saliasi E, van den Berg V, et al. Effects of physical activity interventions on cognitive and academic performance in children and adolescents: a novel combination of a systematic review and recommendations from an expert panel. $\mathrm{Br} J$ Sports Med 2019;53:640-7.

25 Norris $E$, van Steen T, Direito A, et al. Effects of physically active lessons on activity, health and education outcomes: an updated systematic review and meta-analysis. Res Q Exerc Sport 2017;88:149-68.

26 Moher D, Liberati A, Tetzlaff J. Preferred reporting items for systematic reviews and meta-analyses: the PRISMA statement. Ann Intern Med 2009;151:264-9.

27 Cochrane Collaboration. Covidence 2017.

28 Hoffmann TC, Glasziou PP, Boutron I, et al. Better reporting of interventions: template for intervention description and replication (TIDieR) checklist and guide. BMJ 2014;348:g1687

29 Michie S, Richardson M, Johnston M, et al. The behavior change technique taxonomy (V1) of 93 hierarchically clustered techniques: building an international consensus for the reporting of behavior change interventions. Ann Behav Med 2013;46:81-95.

30 Higgins JPT, Altman DG, Gøtzsche PC, et al. The Cochrane collaboration's tool for assessing risk of bias in randomised trials. BMJ 2011;343:d5928.

31 World Health Organisation. Report on the Commission of ending childhood obesity. Geneva: World Health Organisation, 2016.

32 Viechtbauer W. Conducting Meta-Analyses in $R$ with the metafor Package. J Stat Softw 2010;36

33 Cohen J. A power primer. Psychol Bull 1992;112:155-9.

34 Duval S, Tweedie R. Trim and fill: a simple Funnel-Plot-Based method of testing and adjusting for publication bias in meta-analysis. Biometrics 2000;56:455-63.

35 Helgeson JL. The impact of physical activity on academics in English classes at the junior high school level. Dissertation Abstracts International Section A: Humanities and Social Sciences 2013;74.

36 Liu A, Hu X, Ma G, et al. Evaluation of a classroom-based physical activity promoting programme. Obes Rev 2008;9(Suppl 1):130-4.

37 Martin R, Murtagh E. Active classrooms: a cluster randomized controlled trial evaluating the effects of a movement integration intervention on the physical activity levels of primary school children. J Phys Act Health 2017;14:290-300.

38 Miller S, Gildea A, Sloan S, et al. Physically active lessons: evaluation report and executive summary. London: Education Endowment Foundation, 2015.

39 Szabo-Reed AN, Willis EA, Lee J, et al. Impact of three years of classroom physical activity bouts on Time-on-Task behavior. Med Sci Sports Exerc 2017:49:2343-50.

40 de Greeff JW, Hartman E, Mullender-Wijnsma MJ, et al. Long-Term effects of physically active academic lessons on physical fitness and executive functions in primary school children. Health Educ Res 2016;31:185-94.

41 de Greeff JW, Hartman E, Mullender-Wijnsma MJ, et al. Effect of physically active academic lessons on body mass index and physical fitness in primary school children. J Sch Health 2016:86:346-52.

42 Mullender-Wijnsma MJ, Hartman E, de Greeff JW, et al. Improving academic performance of school-age children by physical activity in the classroom: 1-year program evaluation. J Sch Health 2015;85:365-71.

43 Mullender-Wijnsma MJ, Hartman E, de Greeff JW, et al. Physically active math and language lessons improve academic achievement: a cluster randomized controlled trial. Pediatrics 2016;137:e20152743-9. 
44 Donnelly JE, Hillman CH, Greene JL, et al. Physical activity and academic achievement across the curriculum: results from a 3-year cluster-randomized trial. Prev Med 2017:99:140-5.

45 Duncan M, Cunningham A, Eyre E. A combined movement and story-telling intervention enhances motor competence and language ability in pre-schoolers to a greater extent than movement or story-telling alone. Eur Phys Educ Rev 2017; $1356336 X$.

46 Vazou S, Skrade MAB. Intervention integrating physical activity with math: math performance, perceived competence, and need satisfaction. Int J Sport Exerc Psychol 2017; 15:508-22.

47 Gammon C, Morton K, Atkin A, et al. Introducing physically active lessons in UK secondary schools: feasibility study and pilot cluster-randomised controlled trial. BMJ Open 2019;9:e025080.

48 Norris $E$, Shelton N, Dunsmuir S, et al. Virtual field trips as physically active lessons for children: a pilot study. BMC Public Health 2015;15:366

49 Graham DJ, Lucas-Thompson RG, O'Donnell MB. Jump in! an investigation of school physical activity climate, and a pilot study assessing the acceptability and feasibility of a novel tool to increase activity during learning. Front Public Health 2014;2.

50 Grieco LA, Jowers EM, Bartholomew JB. Physically active academic lessons and time on task: the moderating effect of body mass index. Med Sci Sports Exerc 2009:41:1921-6.

51 Grieco LA, Jowers EM, Errisuriz VL, et al. Physically active vs. sedentary academic lessons: a dose response study for elementary student time on task. Prev Med 2016:89:98-103.

52 Mavilidi M-F, Okely AD, Chandler $P$, et al. Infusing physical activities into the classroom: effects on preschool children's geography learning. Mind, Brain, and Education 2016;10:256-63.

53 Bartholomew JB, Jowers EM, Roberts G, et al. Active learning increases children's physical activity across demographic subgroups. Trans/ J Am Coll Sports Med 2018;3:1-9.

54 Donnelly JE, Greene JL, Gibson CA, et al. Physical activity across the curriculum (PAAC): a randomized controlled trial to promote physical activity and diminish overweight and obesity in elementary school children. Prev Med 2009;49:336-41.

55 Mavilidi M-F, Okely AD, Chandler P, et al. Effects of integrating physical activities into a science lesson on preschool children's learning and enjoyment. App/ Cogn Psychol 2017;31:281-90.

56 Shoval E, Sharir T, Arnon M, et al. The effect of integrating movement into the learning environment of kindergarten children on their academic achievements. Early Childhood Educ J 2018;46:355-64.

57 Kirk SM, Kirk EP. Sixty minutes of physical activity per day included within preschool academic lessons improves early literacy. J Sch Health 2016;86:155-63.

58 Kirk SM, Vizcarra CR, Looney EC, et al. Using physical activity to teach academic content: a study of the effects on literacy in head start preschoolers. Early Childhood Educ J 2014:42:181-9.

59 Trost SG, Fees B, Dzewaltowski D. Feasibility and efficacy of a "move and learn" physical activity curriculum in preschool children. J Phys Act Health 2008;5:88-103.

60 Reed JA, Einstein G, Hahn E, et al. Examining the impact of integrating physical activity on fluid intelligence and academic performance in an elementary school setting: a preliminary investigation. J Phys Act Health 2010;7:343-51.

61 Klinkenborg A. The effect of physical activity on science competence and attitude towards science content 2011

62 Beck MM, Lind RR, Geertsen SS, et al. Motor-Enriched learning activities can improve mathematical performance in preadolescent children. Front Hum Neurosci 2016;10:645-45.

63 Have M, Nielsen JH, Ernst MT, et al. Classroom-based physical activity improves children's math achievement - A randomized controlled trial. PLoS One 2018;13:e0208787.

64 Mahar MT, Murphy SK, Rowe DA, et al. Effects of a classroom-based physical activity program on physical activity and on On-Task behavior in elementary school children. Med Sci Sports Exer 2006;38(Supplement):S80-80.

65 Reznik M, Wylie-Rosett J, Kim M, et al. A classroom-based physical activity intervention for urban kindergarten and first-grade students: a feasibility study. Child Obes 2015;11:314-24.
66 Riley N, Lubans DR, Holmes K, et al. Findings from the easy minds cluster randomized controlled trial: evaluation of a physical activity integration program for mathematics in primary schools. J Phys Act Health 2016;13:198-206.

67 Mavilidi M-F, Okely AD, Chandler P, et al. Effects of Integrated Physical Exercises and Gestures on Preschool Children's Foreign Language Vocabulary Learning. Educ Psychol Rev 2015;27:413-26.

68 McKenzie T. SOFIT (system of observing fitness instruction time): generic description and procedures manual: San Diego state university 2006.

69 Callcott D, Hammond L, Hill S. The synergistic effect of teaching a combined explicit movement and phonological awareness program to preschool aged students. Early Child Educ J 2015;43:201-11.

70 Elofsson J, Englund Bohm A, Jeppsson C, et al. Physical activity and music to support pre-school children's mathematics learning. Education 3-13 2018;46:483-93.

71 Erwin H, Fedewa A, Ahn S. Student academic performance outcomes of a classroom physical activity intervention: a pilot study. IEJEE 2012:4:473-87.

72 Fedewa AL, Ahn S, Erwin H, et al. A randomized controlled design investigating the effects of classroom-based physical activity on children's fluid intelligence and achievement. Sch Psychol Int 2015;36:135-53.

73 Hraste M, De Giorgio A, Jelaska PM, et al. When mathematics meets physical activity in the school-aged child: the effect of an integrated motor and cognitive approach to learning geometry. PLoS One 2018;13:e0196024.

74 Leandro CR, Monteiro E, Melo F. Interdisciplinary working practices: can creative dance improve math? Research in Dance Education 2018;19:74-90.

75 Vetter M, O'Connor H, O'Dwyer $\mathrm{N}$, et al. Learning "Math on the Move": Effectiveness of a Combined Numeracy and Physical Activity Program for Primary School Children. $J$ Phys Act Health 2018;15:492-8.

76 Mahar MT. Impact of short bouts of physical activity on attention-to-task in elementary school children. Prev Med 2011;52(Suppl 1):S60-S64.

77 Ridgers ND, Timperio A, Cerin E, et al. Compensation of physical activity and sedentary time in primary school children. Med Sci Sports Exerc 2014;46:1564-9.

78 Beets MW, Okely A, Weaver RG, et al. The theory of expanded, extended, and enhanced opportunities for youth physical activity promotion. Int J Behav Nutr Phys Act 2016;13.

79 Reilly JJ, Penpraze V, Hislop J, et al. Objective measurement of physical activity and sedentary behaviour: review with new data. Arch Dis Child 2008;93:614-9.

80 Freedman DS, Sherry B. The validity of BMI as an indicator of body fatness and risk among children. Pediatrics 2009;124(Supplement 1):S23-S34.

81 Donnelly JE, Hillman CH, Castelli D, et al. Physical activity, fitness, cognitive function, and academic achievement in children: a systematic review. Med Sci Sports Exerc 2016:48:1197-222.

82 Barr-Anderson DJ, AuYoung M, Whitt-Glover MC, et al. Integration of short bouts of physical activity into organizational routine a systematic review of the literature. Am J Prev Med 2011;40:76-93.

83 Benjamin Neelon SE, Hesketh KR, van Sluijs EM. Will physically active lessons improve academic achievement for all or widen the achievement gap? Pediatrics 2016;137:e20154137.

84 Effective Public Health Practice Project. Quality assessment tool for quantitative studies. Hamilton, ON: McMaster University, 2008.

85 Jackson D, Walter G, Daly J, et al. Editorial: Multiple outputs from single studies: acceptable division of findings vs. 'salami' slicing. J Clin Nurs 2014:23:1-2.

86 Routen AC, Chalkley AE, Sherar LB. Getting a grip (getting research into practice) on movement integration in the school classroom. Physical Therapy Reviews 2017:22:139-46.

87 Webster CA, Russ L, Vazou S, et al. Integrating movement in academic classrooms: understanding, applying and advancing the knowledge base. Obes Rev 2015;16:691-701

88 Naylor P-J, Nettlefold L, Race D, et al. Implementation of school based physical activity interventions: a systematic review. Prev Med 2015;72:95-115.

89 Greenhalgh T, Jackson C, Shaw S, et al. Achieving research impact through co-creation in community-based health services: literature review and case study. Milbank $Q$ 2016;94:392-429.

90 Michie S, West R, Campbell R, et al. ABC of Behaviour Change Theories. Great Britain: Silverback Publishing, 2014. 